\title{
INHIBITION OF LISTERIA MONOCYTOGENES IN MINAS FRESCAL CHEESE BY FREE AND NANOVESICLE- ENCAPSULATED NISIN
}

\section{Patrícia da Silva Malheiros, Daniel Joner Daroit, Adriano Brandelli*}

Laboratório de Bioquímica e Microbiologia Aplicada, Departamento de Ciência de Alimentos, Universidade Federal do Rio Grande do Sul, Porto Alegre, RS, Brasil.

\begin{abstract}
The effectiveness of free and nanovesicle-encapsulated nisin to control Listeria monocytogenes in Minas Frescal cheese was investigated. Commercial nisin was encapsulated into liposomes of partially purified soy lecithin. Free $(0.1 \mathrm{mg} / \mathrm{mL}$ and $0.25 \mathrm{mg} / \mathrm{mL})$ and nanovesicle-encapsulated nisin $(0.25 \mathrm{mg} / \mathrm{mL})$ were applied onto the surface of cheese samples, and L. monocytogenes was inoculated before incubation at $6-8{ }^{\circ} \mathrm{C}$ for 28 days. A bactericidal effect was observed with $0.25 \mathrm{mg} / \mathrm{mL}$ free nisin; a bacteriostatic effect was observed for liposome-encapsulated nisin and $0.1 \mathrm{mg} / \mathrm{mL}$ free nisin. Free nisin was more efficient than nisin-loaded liposomes in controlling L. monocytogenes. Possible reasons for this behavior, and also the significance of nisin to soft cheeses are discussed. Nisin acted as a suitable barrier within hurdle technology, potentially extending the shelf-life and safety of fresh cheeses.
\end{abstract}

Key words: nisin, liposome, encapsulation, cheese, Listeria monocytogenes

\section{INTRODUCTION}

Food preservation and microbiological quality represent major concerns and challenges to the food industry. Much effort has been focused on the application of antimicrobial peptides as potential biopreservatives in hurdle technology. The most extensively studied bacteriocin is nisin, which is approved for food applications and has gained a widespread industrial significance. This bacteriocin, produced by strains of Lactococus lactis subsp. lactis, shows a broad inhibitory spectrum against Gram-positive bacteria like Listeria spp. and Staphylococcus spp., also inhibiting the outgrowth of spores of
Bacilli and Clostridia (1). Nisin is frequently added directly to food systems as commercial products, an application in which loss of antimicrobial activity usually occurs over time because of enzymatic degradation and interactions with food components, such as proteins and lipids (19).

Nanotechnology is recognized as a potential source of novel products and processes for the food industry (17). However, only limited investigation in nanotechnology has been performed on foods and food-related products, and the global development of nanofoods seems to be on its initial stage (6). Thus, encapsulation technology is exploited as an alternative to protect antimicrobials, potentially enhancing their

*Corresponding Author. Mailing address: Laboratório de Bioquímica e Microbiologia Aplicada, Departamento de Ciência de Alimentos (ICTA), Universidade Federal do Rio Grande do Sul, Av. Bento Gonçalves 9500, 91501-970 Porto Alegre, RS, Brazil.; Tel.: +5551 33086249 Fax +5551 33087048 .; E-mail: abrand@ufrgs.br 
efficacy and stability in foods (11). Encapsulation into liposome, composed by one or more phospholipid bilayers encapsulating a volume of aqueous media, appears as promising alternative (13).

Fresh cheeses generally have a short shelf-life, even under refrigeration. Minas Frescal is an example of such cheese, presenting high $\mathrm{pH}$ (4.9-6.7), high moisture content (>55\%), and low percentage of salt $(1.4-1.6 \%)(4,5,18)$. These characteristics facilitate the development of bacteria that, in addition to limiting the product shelf-life, may pose a health hazard to consumers, since pathogenic bacteria could be found in such cheeses (15). Particularly, the ability to grow under refrigeration makes Listeria monocytogens a foodborne pathogen of special concern to the dairy industry, and this bacterium was previously found in fresh and soft cheeses $(4,5,8)$. The aim of this study was to evaluate the effectiveness of free (unencapsulated) and nanovesicle-encapsulated nisin to control L. monocytogenes in Minas Frescal fresh cheese surfaces at $6-8^{\circ} \mathrm{C}$.

\section{MATERIALS AND METHODS}

\section{Nisin encapsulation}

Commercial nisin (Nisaplin), containing 2.5\% pure nisin A, was purchased from Danisco Brasil Ltda. A nisin solution was prepared with $0.01 \mathrm{M} \mathrm{HCl}$ and was filter-sterilized through $0.22 \mu \mathrm{m}$ membranes (Millipore). Before each experiment, nisin was diluted with $10 \mathrm{mM}$ phosphate buffer ( $\mathrm{pH} \mathrm{6.4)}$ to reach concentrations of 0.1 and $0.25 \mathrm{mg} / \mathrm{mL}$ pure nisin.

Nisin encapsulation into partially purified soybean phosphatidylcholine liposomes was carried out by the thin-film hydration method (9). The size of the unilamellar nanovesicles was determined by light scattering (22). Encapsulated and unencapsulated nisin were separated by ultrafiltration through 10-kDa cut-off membranes (Ultracel YM-10 Membrane, Millipore). Entrapment efficiency (EE) was determined using the agar diffusion method, and calculated as previously reported (9).

\section{Antimicrobial activity assay}

Antimicrobial activity of free and encapsulated nisin was detected by the agar diffusion assay performed in BHI agar plates inoculated with L. monocytogenes ATCC 7644, and expressed as activity units per $\mathrm{mL}(\mathrm{AU} / \mathrm{mL})(9)$.

L. monocytogenes ATCC 7644 was maintained on BrainHeart Infusion (BHI) agar plates at $4^{\circ} \mathrm{C}$, and subcultured periodically. Before each experiment, this strain was grown in $\mathrm{BHI}$ broth at $37^{\circ} \mathrm{C}$ for $18-24 \mathrm{~h}$ in an orbital shaker (125 rpm).

\section{Inhibition of L. monocytogenes in Minas cheese}

Free $(0.1 \mathrm{mg} / \mathrm{mL}$ and $0.25 \mathrm{mg} / \mathrm{mL})$ or liposomeencapsulated nisin $(0.25 \mathrm{mg} / \mathrm{mL})$ were applied onto the surface of Minas Frescal cheese cubes of approximately $10 \mathrm{~g}$, and maintained for $30 \mathrm{~min}$. An overnight culture of $L$. monocytogenes was diluted in saline solution (8.5 g/L NaCl). Then, $500 \mu \mathrm{L}$ of this suspension ( 4.5 $\log \mathrm{CFU} / \mathrm{mL})$ was inoculated into the cheese surface before incubation at $6-8^{\circ} \mathrm{C}$ for 28 days. At defined intervals, cheese samples (10 g) were homogenized with $90 \mathrm{ml}$ of Listeria Enrichment Broth (Acumedia, Baltimore, MA, USA) in a blender for $60 \mathrm{~s}$, followed by decimal serial dilutions. Counts were carried out in duplicate on Oxford Listeria selective agar (Acumedia) plates.

\section{Recovery of nisin activity}

For recovery of nisin activity, free and nanovesicleencapsulated nisin $(0.25 \mathrm{mg} / \mathrm{mL})$ were applied onto the surface of $5 \mathrm{~g}$ cheese cubes and two methods were tested: (a) the cubes were homogenized with $10 \mathrm{mM}$ phosphate buffer ( $\mathrm{pH}$ 6.4); and (b) the cubes were homogenized with $10 \mathrm{mM}$ phosphate buffer ( $\mathrm{pH}$ 6.4) containing $0.2 \%(\mathrm{w} / \mathrm{v})$ Tween 80 and the mixture was heated for $15 \mathrm{~min}$ at $60{ }^{\circ} \mathrm{C}$ in a water bath (2). Then, for both methods, the homogenates were centrifuged at $10,000 \times \mathrm{g}$ for $30 \mathrm{~min}$, and the antimicrobial activity was assessed by the agar diffusion assay.

\section{RESULTS}

The antimicrobial activity of 0.25 and $0.1 \mathrm{mg} / \mathrm{mL}$ free 
nisin was 400 and 200 AU/mL, respectively, and liposomeencapsulated nisin showed an antimicrobial activity of 400 AU/mL. Nisin-loaded liposomes presented a mean diameter of $140 \mathrm{~nm}$, with an EE of 100\% (data not shown). Initial counts of
L. monocytogenes inoculated into Minas Frescal cheese were around $2.7 \log \mathrm{CFU} / \mathrm{mL}$. In control treatments (without nisin), counts increased to approximately $5 \log \mathrm{CFU} / \mathrm{mL}$ after 28 days of incubation under refrigeration (Table 1).

Table 1. Counts of inoculated Listeria monocytogenes in Minas Frescal cheese under refrigeration $\left(6-8^{\circ} \mathrm{C}\right)$, treated with free or liposome-encapsulated nisin ${ }^{\mathrm{a}}$

\begin{tabular}{ccccc}
\hline Time (days) & Control & $\begin{array}{c}\text { Free nisin } \\
\mathbf{( 0 . 1 0} \mathbf{~ m g} / \mathbf{m l})\end{array}$ & $\begin{array}{c}\text { Free nisin } \\
\mathbf{( 0 . 2 5} \mathbf{~ m g} / \mathbf{m l})\end{array}$ & $\begin{array}{c}\text { Encapsulated nisin } \\
\mathbf{( 0 . 2 5} \mathbf{~ m g} / \mathbf{m l})\end{array}$ \\
\hline 0 & $2.87 \pm 0.10$ & $2.79 \pm 0.00$ & $2.87 \pm 0.10$ & $2.87 \pm 0.10$ \\
7 & $3.03 \pm 0.40$ & $1.98 \pm 0.14$ & n.d. & $1.97 \pm 0.04$ \\
14 & $3.75 \pm 0.76$ & $2.60 \pm 0.22$ & n.d. & $2.19 \pm 0.28$ \\
21 & $4.15 \pm 0.30$ & $2.48 \pm 0.57$ & n.d. & $3.02 \pm 0.12$ \\
28 & $5.07 \pm 0.41$ & $3.21 \pm 0.98$ & n.d. & $3.42 \pm 0.60$ \\
\hline
\end{tabular}

${ }^{\mathrm{a}}$ The values represent mean $\log \mathrm{CFU} / \mathrm{mL} \pm \mathrm{SD}$ of two replicates; n.d., not detected.

Treatment of cheese with nisin (free or encapsulated forms) prior to inoculation with $L$. monocytogenes resulted in lower counts when compared to the controls. Regarding free nisin, the higher concentration $(0.25 \mathrm{mg} / \mathrm{mL})$ exhibited a bactericidal effect against $L$. monocytogenes. The inferior detection limit of the method employed in microbial counts ( 1.69 $\log$ CFU/mL) (12) was reached after 7 days, and such effect was maintained until day 28 (Table 1). At lower concentration $(0.1 \mathrm{mg} / \mathrm{mL})$, free nisin presented a bacteriostatic effect throughout the experiment, although L. monocytogenes counts tended to increase as time progressed. Similarly to 0.1 $\mathrm{mg} / \mathrm{mL}$ free nisin, liposome-encapsulated nisin also presented a bacteriostatic effect (Table 1).

Although attempts to recover nisin from the cheese samples were not successful (data not shown), it appeared that the rate of nisin release from liposomes was sufficient to inhibit L. monocytogenes growth in comparison to the control (Table 1).

\section{DISCUSSION}

The antimicrobial effect of nisin and other bacteriocins in cheeses is mainly investigated through the direct addition of the bacteriocin during cheese manufacture or post-production, or by inoculation of cheese milk with bacteriocinogenic starters
$(3,16,19)$. However, the successful utilization of encapsulated nisin in reducing L. monocytogenes counts in fluid model systems $(10,20,22)$ also suggests its potential usefulness in (semi-)solid matrices, such as cheeses. Liposomes were selected as nisin carriers due to the presence of both lipid and aqueous phases in its structure, allowing the entrapment, delivery, and release of water-soluble, lipid-soluble, and amphiphilic materials (13). As nisin is a cationic amphiphilic peptide, this bacteriocin could be both encapsulated in the inner aqueous phase of liposomes and immobilized into liposome membranes (11).

Differences in the effect of free (bactericidal) and encapsulated nisin (bacteriostatic) at $0.25 \mathrm{mg} / \mathrm{mL}$ might indicate that nisin have been strongly associated to the phospholipidic vesicles, as previously suggested for fluid systems (10), being gradually released from liposomes. Insertion of nisin into liposomes of PC, a lipid not commonly found in prokaryotic membranes, might cause the stabilization of the nanovesicles, possibly through a lowering of curvature stresses (21). Accordingly, nisin-loaded PC liposomes showed the slowest apparent release of antimicrobial when compared to liposomes manufactured with PC:phosphatidylglycerol (60:40) (20). Additionally, lecithin was showed to inhibit nisin activity, possibly through the formation of stable nisin-phospholipid complexes (7). 
Presence of L. monocytogenes in soft, fresh cheeses is usually related to the utilization of unpasteurized contaminated milk or, when pasteurization is employed, postprocessing contamination $(8,18)$. As counts of $L$. monocytogenes found in such cheeses are probably lower than that employed in this experiment, nisin in its free or encapsulated forms might efficiently inhibit the growth of this pathogen during refrigerated storage. In this context, control of $L$. monocytogenes growth for 28 days is well correlated with the shelf-life of Minas Frescal cheeses (25-33 days) (5).

Nascimento et al (15) reported that nisin application in Minas Frescal cheese gains further importance since counts of L. monocytogenes inoculated into this cheese, manufactured using a commercial starter with adjunct bacteriocinogenic cultures, showed no significant differences when compared to cheeses produced without bacteriocinogenic cultures. On the other hand, according to Naldini et al (14), L. monocytogenes counts remained almost unchanged during storage (25 days at 5 or $10^{\circ} \mathrm{C}$ ) of Minas Frescal cheeses manufactured with the addition of starter culture (traditional process), whereas an increase in counts of 2-3 log cycles was observed in cheeses manufactured by direct acidification (14). These results were attributed to $\mathrm{pH}$ lowering through lactic acid production, and competition of the lactic culture with L. monocytogenes. Listeria spp. was found in $22.6 \%$ and $12.9 \%$ of Minas Frescal cheeses manufactured by direct acidification and by the traditional process, respectively (5). Therefore, both free and encapsulated nisin forms might be employed in Minas Frescal cheeses manufactured either by the traditional process or direct acidification, aiming to restrict $L$. monocytogenes growth if contamination occurs, and adding to the effective safety of these products. Also, the storage of Minas Frescal cheese at $10^{\circ} \mathrm{C}$ increased L. monocytogenes growth when compared to storage at $5^{\circ} \mathrm{C}$ (14), reinforcing the significance of nisin's antimicrobial activity within the hurdle technology concept.

Little information is available on the effect of antimicrobial loaded liposomes in cheese. Previously, liposome-entrapped nisin was reported to improve nisin stability and its inhibitory action against L. monocytogenes in Cheddar cheese matrix during ripening (2). These results, divergent from those obtained in the current study, might be related to differences in the materials and protocols employed: for instance, purified phospholipids and purified nisin $\mathrm{Z}$ were utilized by Benech et al. (2) to produce nisin-loaded liposomes, and the nisin-loaded liposomes were added to milk during cheese manufacture.

Due to the scarce information available on this topic, the current investigation might contribute to assess the feasibility and suitability of applying nisin-loaded nanovesicles in semisolid food matrices, such as cheeses. As encapsulation was observed to protect the starter cultures from the detrimental action of nisin, not affecting the fermentation process during cheese production (2), the possibility to apply nisin-loaded liposomes to milk during the manufacture of Minas Frescal cheese through the traditional process (which employs starter cultures) warrants further investigation.

\section{ACKNOWLEDGEMENTS}

Authors thank the financial support of CAPES and CNPq (Brazil).

\section{REFERENCES}

1. Arauz, L.J.; Jozala, A.F.; Mazzola, P.G.; Vessoni Penna, T.C. (2009). Nisin biotechnological production and application: a review. Trends Food Sci. Technol. 20, 146-154.

2. Benech, R.O.; Kheadr, E.E.; Laridi, R.; Lacroix, C.; Fliss, I. (2002). Inhibition of Listeria innocua in cheddar cheese by addition of nisin $\mathrm{Z}$ in liposomes or by in situ production in mixed culture. Appl. Environ. Microbiol. 68, 3683-3690.

3. Bizani, D.; Morrissy, J.A.C.; Dominguez, A.P.M.; Brandelli, A. (2008). Inhibition of Listeria monocytogenes in dairy products using the bacteriocin-like peptide cerein 8A. Int. J. Food Microbiol. 121, 229-233.

4. Brito, J.R.F.; Santos, E.M.P.; Arcuri, E.F.; Lange, C.C.; Brito, M.A.V.P.; Souza, G.N.; Cerqueira, M.M.P.O.; Beltran, J.M.S.; Call, J.E.; Liu, Y.; Porto-Fett, A.C.S.; Luchansky, J.B. (2008). Retail survey of Brazilian milk and Minas Frescal cheese and a contaminated dairy plant to establish prevalence, relatedness, and sources of Listeria monocytogenes 
isolates. Appl. Environ. Microbiol. 74, 4954-4961.

5. Carvalho, J.D.G.; Viotto, W.H.; Kuaye, A.Y. (2007). The quality of Minas Frescal cheese produced by different technological processes. Food Control 18, 262-267.

6. Chau, C.F., Wu, S.W.; Yen, G.C. (2007) The development of regulations for food nanotechnology. Trends Food Sci. Technol. 18, 269-280.

7. Gänzle, M.G.; Weber, S.; Hammes, W.P. (1999). Effect of ecological factors on the inhibitory spectrum and activity of bacteriocins. Int. J. Food Microbiol. 46, 207-217.

8. Kabuki, D.Y.; Kuaye, A.Y.; Wiedmann, M.; Boor, K.J. (2004). Molecular subtyping and tracking of Listeria monocytogenes in Latinstyle fresh-cheese processing plants. J. Dairy Sci. 87, 2803-2812.

9. Malheiros, P.S, Micheletto, Y.M.S., Silveira, N.P., \& Brandelli, A. (2010). Development and characterization of phosphatidylcholine nanovesicles containing the antimicrobial peptide nisin. Food Res. Int. 43, 1198-1203.

10. Malheiros, P.S.; Daroit, D.J.; Silveira, N.P.; Brandelli, A. (2010) Effect of nanovesicle-encapsulated nisin on growth of Listeria monocytogenes in milk. Food Microbiol. 27, 175-178.

11. Malheiros, P.S.; Daroit, D.J.; Brandelli, A. (2010) Food applications of liposome-encapsulated antimicrobial peptides. Trends Food Sci. Technol. 21, 284-292.

12. Malheiros, P.S.; Brandelli, A.; Noreña, C.P.Z.; Tondo, E. C. (2009). Acid and thermal resistance of a Salmonella enteritidis strain involved in several foodborne outbreaks. J. Food Saf. 29, 302-317.

13. Mozafari, M.R.; Johnson, C.; Hatziantoniou, S.; Demetzos, C. (2008). Nanoliposomes and their applications in food nanotechnology. $J$. Liposome Res. 18, 309-327.

14. Naldini, M.C.M.; Viotto, W.H.; Kuaye, A.Y. (2009). Behaviour of
Listeria monocytogenes inoculated into Minas Frescal cheese made by direct acidification or lactic culture during refrigerated storage. Int. J. Dairy Technol. 62, 361-365.

15. Nascimento, M.S.; Moreno, I.; Kuaye, A.Y. (2008). Applicability of bacteriocin-producing Lactobacillus plantarum, Enterococcus faecium and Lactococcus lactis ssp. lactis as adjunct starter in Minas Frescal cheesemaking. Int. J. Dairy Technol. 61, 352-357.

16. Rodríguez, E.; Calzada, J.; Arqués, J.L.; Rodríguez, J.M.; Nuñez, M.; Medina, M. (2005). Antimicrobial activity of pediocin-producing Lactococcus lactis on Listeria monocytogenes, Staphylococcus aureus and Escherichia coli O157:H7 in cheese. Int. Dairy J. 15, 51-57.

17. Sanguansri, P.; Augustin, M.A. (2006) Nanoscale materials development - A food industry perspective. Trends Food Sci. Technol. 17, 547-556.

18. Silva, I.M.M.; Almeida, R.C.C.; Alves, M.A.O.; Almeida, P.F. (2003). Occurrence of Listeria spp. in critical control points and the environment of Minas Frescal cheese processing. Int. J. Food Microbiol. 81, 241-248.

19. Sobrino-López, A.; Martín-Belloso, O. (2008). Use of nisin and other bacteriocins for preservation of dairy products. Int. Dairy J. 18, 329-343.

20. Taylor, T.M.; Bruce, B.D.; Weiss, J.; Davidson, P.M. (2008). Listeria monocytogenes and Escherichia coli O157:H7 inhibition in vitro by liposome-encapsulated nisin and ethylene diaminetetraacetic acid. $J$. Food Saf. 28, 183-197.

21. Taylor, T.M.; Davidson, P.M.; Bruce, B.D.; Weiss, J. (2005). Ultrasonic spectroscopy and differential scanning calorimetry of liposomalencapsulated nisin. J. Agric. Food Chem. 53, 8722-8728.

22. Teixeira, M.L.; Santos, J.; Silveira, N.P.; Brandelli, A. (2008). Phospholipid nanovesicles containing a bacteriocin-like substance for control of Listeria monocytogenes. Innov. Food Sci. Emerg. Technol. 9, 49-53. 